\title{
Viscometric and Light Scattering Study on Dilute Solution Properties of Cellulose Acetate with a Degree of Substitution of $\mathbf{1 . 7 5}$
}

\author{
Masatoshi SAITo \\ Textile Research Laboratory, Asahi Chemical Industry Company, Ltd., \\ Takatsuki, Osaka 569, Japan
}

(Received October 29, 1982)

\begin{abstract}
KEY WORDS Cellulose Acetate / Viscosity / Light Scattering Unperturbed Chain Dimension / Excluded Volume Effect / Draining Effect /
\end{abstract}

A number of the investigations have been made concerning to the dilute solution properties of cellulose acetate (CA), because of the industrial importance of this polymer. However, except for the studies of Kamide and his coworkers, ${ }^{1-14}$ the degree of substitution (DS) of CA polymers treated has been restricted only to high values. Using the successive solution fractionation (SSF) method, Kamide et al. ${ }^{4-6,12-14}$ prepared fractionated CA samples with DS equal to $0.49,2.46,2.92$ and relatively narrow molecular weight distributions $\left(1.1 \leq M_{w} / M_{n} \leq 1.4 ; M_{w}\right.$ and $M_{n}$ are the weightand number-average molecular weights, respectively). Analysis of light scattering, membrane osmometry, viscosity, and ultracentrifugation data showed that the equilibrium chain rigidity of $\mathrm{CA}$ in $N, N$-dimethylacetamide (DMAc) depended on DS and that the unperturbed chain dimension $(A)$ as well as the persistence length $(q)$ become maxima at $\mathrm{DS} \simeq 2.5 .^{13,15}$

In order to clarify the DS dependence of the unperturbed chain dimensions of CA and to evaluate the molecular parameters, we made a study of the dilute solution properties of CA with $\mathrm{DS}=1.75$ by light scattering, membrane osmometry, and viscosity.

\section{EXPERIMENTAL}

A CA sample $\left(\mathrm{DS}=2.46\right.$ and $\left.M_{w}=1.2 \times 10^{5}\right)$ synthesized in a previous study ${ }^{5}$ was hydrolyzed with hydrochloric acid as a catalyst in a $77 \%$ aq acetic acid for about one week. The hydrolyzed CA was recovered by precipitation with methanol and dried in vacuo.

The degree of substitution of this unfractionated CA was determined by back-titration to be 1.75 . From its ${ }^{13} \mathrm{C}$ NMR spectra in deuterated dimethylsulfoxide (DMSO- $d_{6}$ ), the average probabilities that the hydroxyl groups attached to the $\mathrm{C}_{2}, \mathrm{C}_{3}$, and $\mathrm{C}_{6}$ atoms were substituted by the $O$-acetyl groups, i.e., $\left.\left\langle f_{2}\right\rangle,\left\langle f_{3}\right\rangle\right\rangle,\left\langle f_{6}\right\rangle$ were estimated to be $0.45,0.54$, and 0.76 , respectively. The total degree of substitution determined from $\sum_{i=2,3,6}\left\langle f_{i}\right\rangle$ was 1.75 , which is in excellent agreement with that evaluated by the neutralizing method.

The CA (DS =1.75) sample was dissolved in acetone-water $(7: 3, \mathrm{vol} / \mathrm{vol})$ and fractionated by the SSF method with water as the precipitant into 10 almost equal fractions.

The viscosities of the fractions in DMAc were measured by a modified Ubbelohde-type viscometer at $25^{\circ} \mathrm{C}$. The limiting viscosity number $[\eta]$ was determined using the Huggins plot.

The osmotic pressures of the fractions in DMAc at $25^{\circ} \mathrm{C}$ were determined with a Wescan Osmometer M231 (Wescan Instruments, Inc., USA). The membrane was an Ultracella filter-type SM-11539 (Sartorious GmbH, West Germany).

One $w \mathrm{t} \%$ stock solutions of the fractions in DMAc were centrifuged at $3.0 \times 10^{4} \mathrm{~g}$ for $1 \mathrm{~h}$ in a Hitachi model 55p-7 automatic preparative ultracentrifuge to remove gel-like material. The average 
Table I. Results of light scattering, membrane osmometer, and viscosity measurements on $\mathrm{CA}(\mathrm{DS}=1.75)$ at $25^{\circ} \mathrm{C}$

\begin{tabular}{|c|c|c|c|c|c|c|c|c|c|c|c|}
\hline \multirow{2}{*}{$\begin{array}{l}\text { Sample } \\
\text { code }\end{array}$} & \multirow{2}{*}{$M_{w} \times 10^{-4}$} & \multicolumn{3}{|c|}{ Light scattering } & \multicolumn{2}{|c|}{ Osmometry } & \multirow{2}{*}{$M_{w} / M_{n}$} & \multirow{2}{*}{$\frac{\text { Viscosity }}{[\eta]^{\mathrm{c}}}$} & \multirow{2}{*}{$\Phi \times 10^{-23}$} & \multirow{2}{*}{$\alpha_{s}^{d}$} & \multirow{2}{*}{$X^{\mathrm{e}}$} \\
\hline & & $\left\langle S^{2}\right\rangle_{z}^{1 / 2 \mathrm{a}}$ & $\left\langle S^{2}\right\rangle_{w}^{1 / 2}$ & $A_{2}{ }^{\mathrm{b}}$ & $M_{n} \times 10^{-4}$ & $A_{2}$ & & & & & \\
\hline $\mathrm{KS} 2-1$ & - & - & - & - & - & - & - & 62 & - & - & - \\
\hline KS2-2 & 3.75 & 1.51 & 1.38 & 9.8 & 2.76 & 9.2 & 1.36 & 86 & 0.94 & $1.02_{8}$ & 0.8 \\
\hline $\mathrm{KS} 2-3$ & 4.38 & 1.67 & 1.47 & 9.6 & 3.43 & 1.3 & 1.28 & 96 & 1.00 & $1.02_{9}$ & 1.0 \\
\hline KS2-4 & - & - & - & - & - & - & - & 116 & - & - & - \\
\hline KS2-5 & 5.53 & 1.96 & 1.75 & 9.5 & - & - & - & 122 & 1.00 & $1.02_{9}$ & 1.0 \\
\hline KS2-6 & 6.15 & 2.06 & 1.84 & 9.5 & 4.67 & 10.9 & 1.31 & 132 & 1.03 & $1.03_{1}$ & 1.1 \\
\hline KS2-7 & - & - & - & - & - & - & - & 144 & - & - & - \\
\hline $\mathrm{KS} 2-8$ & 8.23 & 2.37 & 2.12 & 8.3 & - & - & - & 157 & 1.07 & $1.03_{2}$ & 1.2 \\
\hline KS2-9 & 10.0 & 2.55 & 2.28 & 6.8 & 7.2 & 9.8 & 1.39 & 165 & 1.10 & $1.03_{1}$ & 1.2 \\
\hline KS2-10 & 13.1 & 2.95 & 2.63 & 6.0 & - & - & - & 196 & 1.10 & $1.03_{0}$ & 1.3 \\
\hline
\end{tabular}

a $10^{-6} \mathrm{~cm}$.

b $10^{-4} \mathrm{~cm}^{3} \mathrm{~mol} \mathrm{~g}^{-2}$.

c $\mathrm{cm}^{3} \mathrm{~g}^{-1}$

d Estimated using penetration function $\psi$.

e Estimated by method $1 \mathrm{~A}^{17}$.

of the specific refractive index increments $(\mathrm{d} n / \mathrm{d} c)$ of three fractions in DMAc was $0.046\left(\mathrm{~cm}^{3} \mathrm{~g}^{-1}\right)$ at $25^{\circ} \mathrm{C}$.

Light scattering measurements were made at $25^{\circ} \mathrm{C}$ with a FICA model 42000 photogoniometer, using unpolarized light (wavelength $\lambda_{0}=436 \mathrm{~nm}$ ) in a scattering angle range from $30^{\circ}$ to $150^{\circ}$.

\section{RESULTS AND DISCUSSION}

The results from light scattering, osmotic pressure, and viscosity measurements on CA (DS= 1.75) fractions in DMAc at $25^{\circ} \mathrm{C}$ are summarized in Table I. The polydispersity parameter $M_{w} / M_{n}$ averaged for all fractions was 1.34 . The measured $z$-average radii of gyration $\left(\left\langle S^{2}\right\rangle_{z}^{1 / 2}\right)$ were converted to weight-average radii of gyration $\left(\left\langle S^{2}\right\rangle_{w}^{1 / 2}\right)$, assuming the Schulz-Zimm molecular weight distribution function with $M_{w} / M_{n}=1.34$. The tenth and eleventh columns of Table I show the Flory viscosity parameter $\Phi$ and the linear expansion factor $\alpha_{s}\left(\equiv\left\langle S^{2}\right\rangle^{1 / 2} /\left\langle S^{2}\right\rangle_{0}^{1 / 2}\right.$; the subscript 0 denotes the unperturbed state). The latter was estimated from the data for $M_{w}, A_{2}$, and $\left\langle S^{2}\right\rangle_{z}^{1 / 2}$ in DMAc, using the expression of Kurata-Fukatsu-SotobayashiYamakawa $^{16}$ (KFSY) for the penetration function $\psi$. The draining parameter $X$ in the twelveth column of Table I was determined by method 1A described previously. ${ }^{17}$

Figures $1 \mathrm{a}-1 \mathrm{c}$ depict the molecular weight dependence of $[\eta],\left\langle S^{2}\right\rangle_{z}^{1 / 2}$, and $\Phi$ for the CA (DS = 1.75) fractions (filled circles) in DMAc. In these figures the literature data on CA $(\mathrm{DS}=0.49)^{12}$ (open circles), $\mathrm{CA}(\mathrm{DS}=2.46)^{13}$ (triangles), and $\mathrm{CA}$ $(\mathrm{DS}=2.92)^{6}$ (rectangles) in DMAc at $25^{\circ} \mathrm{C}$ are shown for comparison. The following MarkHouwink-Sakurada (MHS) equation was derived for the CA ( $D S=1.75)$ fractions in DMAc by the least-squares method:

$$
[\eta]=9.58 \times 10^{-2} M_{w}^{0.65} \quad\left(\mathrm{~cm}^{3} \mathrm{~g}^{-1}\right)
$$

The exponent $a$ in the MHS equation

$$
[\eta]=K_{\mathrm{m}} M^{a}
$$

( $K_{\mathrm{m}}$ and $a$ are the parameters characteristic of a given polymer/solvent system at a given temperature) decreases in the order: $\mathrm{CA}(\mathrm{DS}=2.46) \gg \mathrm{CA}$ $(\mathrm{DS}=2.92)>\mathrm{CA}(\mathrm{DS}=1.75)>\mathrm{CA}(\mathrm{DS}=0.49)$. The relation between $\left\langle S^{2}\right\rangle_{z}^{1 / 2}$ and $M_{w}$ for the CA (DS $=1.75)$ fractions in DMAc is represented by

$$
\left\langle S^{2}\right\rangle_{z}^{1 / 2}=0.38 \times 10^{-8} M_{w}^{0.52} \quad(\mathrm{~cm})
$$

Compared at the same $M_{w}$, the $\left\langle S^{2}\right\rangle_{z}^{1 / 2}$ value for the CA (DS $=2.46) / D M A c$ system is larger than those of other CA/DMAc systems in the range of $M_{w} \leq 10^{6}$, suggesting that the CA molecule in 


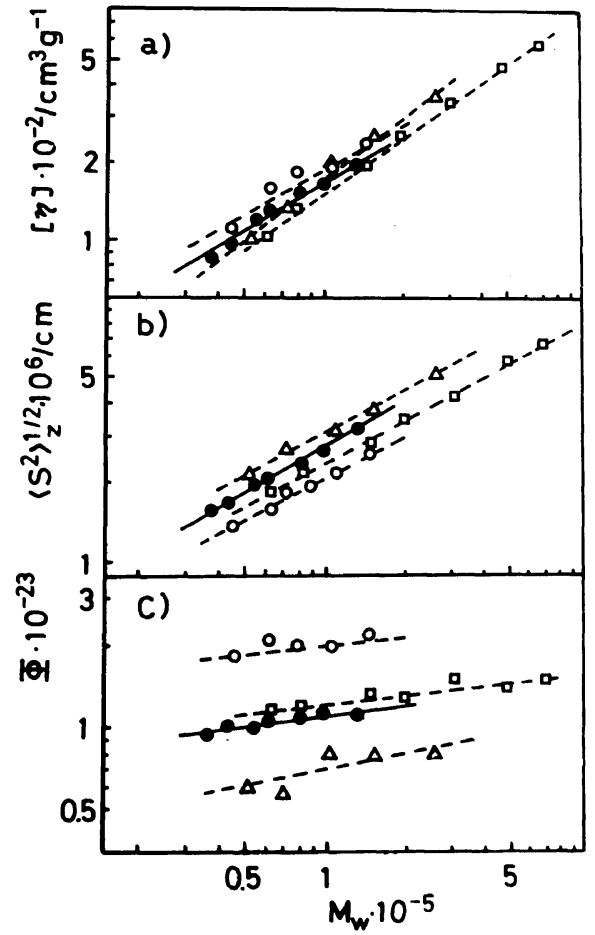

Figure 1. a) Molecular weight dependence of limiting viscosity number $[\eta]$; b) $z$-average radius of gyration $\left\langle S^{2}\right\rangle_{z}^{1 / 2}$, and c) Flory's viscosity parameter $\Phi$ of CA with various $\mathrm{DS}$ in DMAc at $25^{\circ} \mathrm{C}$. Closed circles, $\mathrm{CA}(\mathrm{DS}=$ $1.75)$; open circles, $\mathrm{CA}(\mathrm{DS}=0.49)$; triangles, $\mathrm{CA}(\mathrm{DS}=$ 2.46); rectangles, $\mathrm{CA}(\mathrm{DS}=2.92)$. Full line represents data for CA (DS =1.75) and broken lines, those for CA $(\mathrm{DS}=0.49)$, CA (DS $=2.46)$, and $\mathrm{CA}(\mathrm{DS}=2.92)$.

DMAc becomes most rigid at $\mathrm{DS}=2.46$.

The value of $\Phi$ for the CA (DS $=1.75$ ) fractions in DMAc depends on molecular weight as follows:

$$
\Phi=0.26 \times 10^{23} M_{w}^{0.12}
$$

A similar significant molecular weight dependence of $\Phi$ was found for other CA in the same solvent. It is noted that even for the highest molecular weight fraction of CA (DS=1.75), the $\Phi$ value is about $60 \%$ smaller than the theoretical limiting value $2.87 \times 10^{23}$ for non-draining and unperturbed linear polymers and hence the draining effect is not negligible for CA (DS $=1.75)$ in DMAc.

The $\alpha_{\mathrm{s}}$ values of the CA $(\mathrm{DS}=1.75)$ fractions in DMAc are smaller than 1.03 , so that the excludedvolume effect on CA (DS $=1.75)$ in DMAc is as small as that on CA with other DS in DMAc. ${ }^{6,12,13}$

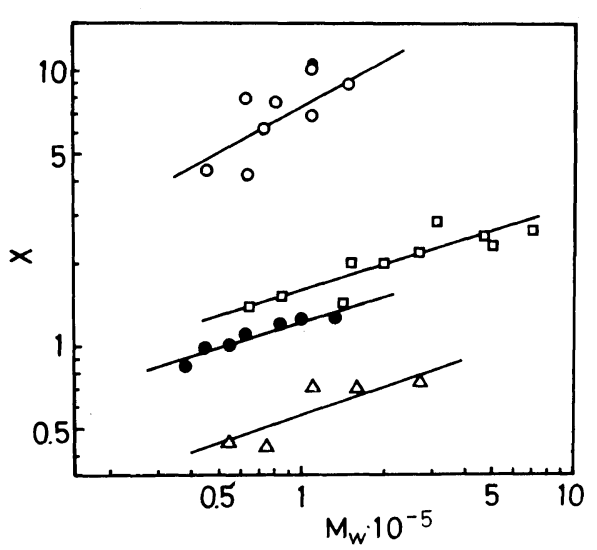

Figure 2. Molecular weight dependence of the draining parameter $X$ of CA with various DS in DMAc. The symbols have the same meaning as in Figure 1. Full lines represent the relation between $X$ and $M_{w}$ determined by the least-squares method from the data for CA with various DS.

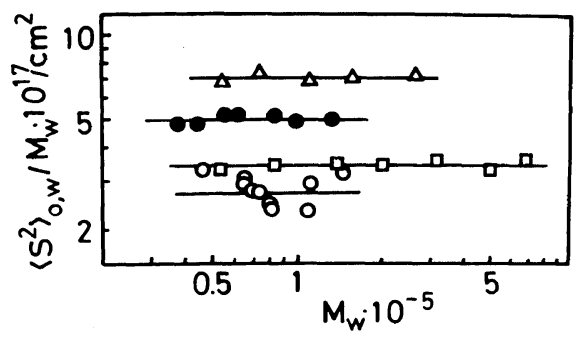

Figure 3. Molecular weight dependence of the meansquare weight-average radius of gyration in the unperturbed state relative to $M_{w}\left(\left\langle S^{2}\right\rangle_{0, w} / M_{w}\right)$ for CA with various DS in DMAc. The symbols have the same meaning as in Figure 1. Full lines represent the relation between $\left\langle S^{2}\right\rangle_{0, w} / M_{w}$ and $M_{w}$ determined by the leastsquares method from the data for CA with various DS.

The $X$ values of the CA (DS $=1.75$ ) fractions in DMAc range from 0.8 to 1.3 . The draining effect on CA/DMAc systems decreases in the order: CA $(\mathrm{DS}=2.46) \gg \mathrm{CA}(\mathrm{DS}=1.75) \geq \mathrm{CA}(\mathrm{DS}=2.92) \gg$ CA (DS $=0.49$ ) (see Figure 2).

Figure 3 shows the log-log plot of the meansquare weight-average radius of gyration in the unperturbed state relative to $M_{w}$, i.e., $\left\langle S^{2}\right\rangle_{0, w} / M_{w}$ vs. $M_{w}$. Here, $\left\langle S^{2}\right\rangle_{0, w}$ was calculated from the values of $\alpha_{\mathrm{s}}\left(\operatorname{method} 2 \mathrm{~B}^{17}\right)$. For CA $(\mathrm{DS}=1.75)$ in DMAc, the ratio $\left\langle S^{2}\right\rangle_{0, w} / M_{w}$ can be regarded, within experimental error, as independent of $M_{w}$ (i.e., $\left.\quad a_{2} \quad\left(\equiv \mathrm{d} \ln \left(\left\langle S^{2}\right\rangle_{0, w} / M_{w}\right) / \mathrm{d} \ln M_{w}\right)=0\right)$. In 
Table II. Unperturbed chain dimensions $A$, conformation parameter $\sigma$, and characteristic ratio $C_{\infty}$ of cellulose acetate with various DS in DMAc at $25^{\circ} \mathrm{C}$, estimated by thermodynamic and hydrodynamic methods

\begin{tabular}{|c|c|c|c|c|}
\hline \multirow{2}{*}{ Methods } & \multicolumn{4}{|c|}{$A \times 10^{8} / \mathrm{cm}$} \\
\hline & $\mathrm{DS}=0.49$ & $\mathrm{DS}=1.75$ & $\mathrm{DS}=2.46$ & $\mathrm{DS}=2.92$ \\
\hline $2 \mathrm{~B}\left(\alpha_{\mathrm{s}}\right.$ from $\left.\psi\right)$ & 1.28 & 1.73 & 2.05 & 1.43 \\
\hline $2 \mathrm{C}\left(a_{2}=0\right)$ & 1.38 & 1.73 & 1.98 & 1.49 \\
\hline $2 \mathrm{E}\left(a_{2}=a_{\Phi}=0\right)$ & 1.12 & 1.12 & 0.79 & 0.89 \\
\hline $2 \mathrm{~F}\left(a_{2}=a_{\Phi}=0\right)$ & 1.14 & 1.16 & 0.92 & 1.00 \\
\hline $2 \mathrm{G}\left(a_{2} \neq 0, a_{\Phi} \neq 0\right)$ & 1.40 & 1.79 & 1.90 & 1.47 \\
\hline $2 \mathrm{~K}\left(a_{2} \neq 0, a_{\Phi} \neq 0\right)$ & 1.45 & 1.73 & 1.85 & 1.46 \\
\hline Most probable $A$ & 1.38 & 1.75 & 1.95 & 1.46 \\
\hline Conformation parameter $\sigma$ & 2.46 & 3.47 & 4.10 & 3.14 \\
\hline Characteristic ratio $C_{\infty}$ & 11.6 & 24.1 & 33.7 & 20.3 \\
\hline
\end{tabular}

other words, $\mathrm{CA}(\mathrm{DS}=1.75)$ as well as $\mathrm{CA}$ with other DS behave as Gaussian chains in DMAc.

Table II presents the unperturbed chain dimension $A\left(\equiv\left(6\left\langle S^{2}\right\rangle_{0} / M\right)^{1 / 2}\right)$ estimated by various methods $(2 \mathrm{~B}-2 \mathrm{~K}) \cdot{ }^{17-19}$ This table includes the $A$ values determined for $\mathrm{CA}$ with different $\mathrm{DS}^{6,12,13,18}$ for comparison. The $A$ values of CA $(\mathrm{DS}=1.75)$ estimated by methods $2 \mathrm{E}$ and $2 \mathrm{~F}$ which neglect the draining effect $\left(a_{\Phi}\left(\equiv \mathrm{d} \ln \Phi / \mathrm{d} \ln M_{w}\right)=0\right)$, are smaller than those estimated by other methods, as was found for other cellulose derivatives, including CA having different DS in DMAc. ${ }^{17-19}$ The most probable $A$, obtained as the average of the values by methods other than $2 \mathrm{E}$ and $2 \mathrm{~F}$ is $1.75 \times 10^{-8}(\mathrm{~cm})$ for CA $(\mathrm{DS}=1.75)$ in DMAc. The conformation parameter $\sigma\left(\equiv A / A_{\mathrm{f}} ; A_{\mathrm{f}}\right.$ is the $A$ for a hypothetical freely rotating chain) and the characteristic ratio $C_{\infty}$ corresponding to the most probable $A$ are also included in Table II. Here we used $0.504 \times 10^{-8}$ (cm) for $A_{\mathrm{f}} \cdot{ }^{13}$ These values of $\sigma$ and $C_{\infty}$ indicated that CA (DS $=1.75)$ is stiffer than CA $(\mathrm{DS}=0.49)$ and CA $(\mathrm{DS}=2.92)$, but more flexible than CA $(\mathrm{DS}=2.46)$, on making a comparison of all these polymers in DMAc. We found by NMR and ultrasonic interferometer measurements that solvation occurs in DMAc solutions of CA (DS $=0.49), C A$ $(\mathrm{DS}=2.46)$, and CA $(\mathrm{DS}=2.92)$ and that this solvation contributes mainly to the chain rigidity of cellulose acetate in DMAc. ${ }^{13}$ Therefore, it may be concluded that the difference in equilibrium chain rigidity among $\mathrm{CA}$ with different $\mathrm{DS}$ is a reflection of the difference in degree of solvation.

Acknowledgments. The author should like to express his sincere gratitude to Dr. Kenji Kamide, General Manager of the Textile Research Laboratory, Asahi Chemical Industry Company, Ltd., for his guidance and interest and to Dr. Kunihiko Okajima, Mr. Toshihiko Matsui, and Mr. Tatsuyuki Abe of the Laboratory for their technical assistance.

\section{REFERENCES}

1. K. Kamide, S. Manabe, and E. Osafune, Makromol. Chem., 168, 173 (1973).

2. K. Kamide, T. Terakawa, and S. Manabe, Sen'i Gakkaishi, 30, T-464 (1974).

3. K. Kamide, T. Terakawa, S. Manabe, and Y. Miyazaki, Sen'i Gakkaishi, 31, T-401 (1975).

4. S. Ishida, H. Komatsu, T. Terakawa, Y. Miyazaki, and K. Kamide, Mem. Fac. Eng., Kanazawa Univ., 12, 103 (1979).

5. K. Kamide, T. Terakawa, and Y. Miyazaki, Polym. J., 11, 285 (1979).

6. K. Kamide, Y. Miyazaki, and T. Abe, Polym. J., 11, 523 (1979).

7. K. Kamide, Y. Miyazaki, and T. Abe, Makromol. Chem., 180, 2801 (1979).

8. H. Suzuki, Y. Miyazaki, and K. Kamide, Netsusokutei, 7, 37 (1980).

9. H. Suzuki, Y. Miyazaki, and K. Kamide, Eur. Polym. J., 16, 703 (1980).

10. K. Kamide, K. Okajima, and M. Saito, Polym. J., 13, 115 (1981). 
11. K. Kamide and K. Okajima, Polym. J., 13, 127 (1981).

12. K. Kamide, M. Saito, and T. Abe, Polym. J., 13, 421 (1981).

13. K. Kamide and M. Saito, Polym. J., 14, 517 (1982).

14. S. Ishida, H. Komatsu, H. Katoh, M. Saito, Y. Miyazaki, and K. Kamide, Makromol. Chem., 183, 3075 (1982).

15. M. Saito, Polym. J., 15, 213 (1983).
16. M. Kurata, M. Fukatsu, H. Sotobayashi, and H. Yamakawa, J. Chem., Phys., 41, 139 (1964).

17. K. Kamide and Y. Miyazaki, Polym. J., 10, 409 (1978).

18. K. Kamide and M. Saito, Eur. Polym. J., 17, 1049 (1981).

19. K. Kamide and M. Saito, Eur. Polym. J., 18, 661 (1982).

20. K. Kamide and M. Saito, unpublished results. 